\title{
Peningkatan Loyalitas Mahasiswa Yang Dipengaruhi Oleh Kualitas Pelayanan Akademik dan Kepuasan Mahasiswa (Studi Kasus Pada Mahasiswa S1 Dan D3 STIESIA Surabaya)
}

\author{
Novianto Eko Nugroho \\ Management Department, School of Economic Indonesia Surabaya. \\ noviantoekonugroho@stiesia.ac.id
}

Diterima: $12 / 30 / 2019$

Direview: $24 / 04 / 2020$

Diterbitkan: 30/07/2020

Hak Cipta (C) 2020 oleh Penulis (dkk) dan Jurnal Sosial Humaniora (JSH)

*This work is licensed under the Creative

Commons Attribution International License (CC BY

4.0).

http://creativecommons.org/licenses/by/4.0/

\section{Subject Area: Economic and Business (Ekonomi dan Bisnis)}

\begin{abstract}
Higher Education is the highest level of education in the education service business in Indonesia which produces bachelor or diploma graduates to meet the competitive needs of the workforce. This study aims to analyze the increase in student loyalty which is influenced by the quality of academic services and satisfaction of S1 and D3 STIESIA Surabaya students. This study uses a quantitative approach to determine the correlation of student loyalty which is influenced by the role of academic service quality and student satisfaction. This research method uses path analysis. The results showed an increase in student loyalty which was influenced by the role of academic service quality due to high student satisfaction.
\end{abstract}

Keywords: Academic Service Quality; Student Satisfaction; Student Loyalty

\section{Pendahuluan}

Persaingan bisnis jasa pendidikan tinggi di era digitalisasi saat ini semakin ketat dan kompetitif seiring dengan adanya kebijakan Menteri Pendidikan, Kebudayaan dan Pendidikan yaitu program kampus merdeka, dimana pada perguruan tinggi diberikan otonomi untuk mengelola lembaga pendidikan mulai pengajuan akreditasi, pengajuan guru besar/profesor, sampai dengan pengajuan pendirian program studi baru. Kesuksesan bisnis jasa pendidikan diwujudkan dalam pemberian pelayanan yang berkualitas kepada stakeholders yaitu mahasiswa dan masyarakat. Sebagaimana dikatakan Cronin dan kawan-kawan bahwa Perguruan tinggi sebagai penyelenggara jasa pendidikan dengan mengembangkan pemahaman yang tidak hanya kualitas dan kepuasan layanan melainkan tentang bagaimana mereka berkesimbungan satu dengan yang lain dan lalu mendorong loyalitas (Cronin et al., 2000). Apalagi, dalam pelaksanaan pengembangan model kerja untuk hubungan konseptual antara kualitas layanan, kepuasan dan loyalitas ditempatkan di atas arahan penelitian masa depan dan minat khusus (Zeithaml, Parasuraman dan Malhotra, 2002). Adanya kebutuhan akan peningkatan kualitas pelayanan akademik diketahui dari tingginya tantangan dan usaha pemenuhan kebutuhan dalam rangka mempersiapkan dan membekali lulusannya hendaknya mampu bersaing dalam memperebutkan pasar kerja membutuhkan kombinasi beragam keterampilan yang berbeda dengan diberikan pada sistem pendidikan tinggi (Marmolejo, World Bank, 2017).

Dengan adanya konsistensi dari penyelenggaran bisnis jasa pendidikan dalam upaya peningkatan mutu pendidikan diwujudkan dengan upaya dalam meningkatkan proses belajar mengajar (PBM), 
penelitian, penyediaan fasilitas dan jaringan dalam membangun hubungan dengan instansi pemerintah, perusahaan nasional maupun multinasional. Davis et al (2003), menjelaskan bahwa kualitas dianggap sebagai sistem defensif tetapi dipandang sebagai strategi kompetitif untuk munculnya pasar baru serta pertumbuhan pangsa pasar. Dengan iklim persaingan yang semakin kompetitif berpotensi akan munculnya gap antara harapan dan persepsi siswa/mahasiswa perlu adanya perbaikan pada standar prosedur layanan. Pada faktor internal terbagi dalam jumlah dan kualitas dosen yang memadai, sarana dan fasilitas yang menunjang, mahasiswa sebagai aset penting yang berpotensi, pelayanan yang memuaskan dan lain-lain sedangkan faktor eksternal adalah hubungan perguruan tinggi dengan masyarakat, pemerintah dan perguruan tinggi lainnya. Berdasarkan faktor internal dan eksternal dituntut agar perguruan tinggi memiliki strategi positioning agar tetap survive. Didalam strategi internal yaitu dengan mengoptimalkan sesuatu yang bersifat operasional dalam perguruan tinggi, seperti proses belajar mengajar, mengatur jadwal ruangan, kuliah, jadwal ujian yang kesemuanya merupakan tugas dari bagian pengajaran dan strategi eksternal yaitu strategi agar suatu perguruan tinggi diminati oleh masyarakat, perusahaan dan pemerintah seperti mengadakan seminar, lokakarya, pelatihan dosen dan mahasiswa, mengikuti karya ilmiah, penelitian yang dapat memberikan hasil, tugas belajar untuk dosen agar memiliki jenjang yang lebih tinggi sehingga ilmu yang didapat bertambah luas (Safrian et al., 2015). Bahwa kualitas layanan dalam pendidikan tinggi adanya gap antara apa yang diharapkan siswa untuk diterima dan persepsi tentang pengiriman aktual (O'Neill dan Palmer, 2004).

Menurut Aswati dan kawan-kawan (Aswati et al, 2015), bahwa bisnis jasa pendidikan tinggi dapat meraih kesuksesan dan kemajuan tidak hanya dilihat dari satu faktor saja, tetapi banyak faktor yang menentukan keberhasilan tersebut melalui faktor internal maupun faktor eksternal. Pada faktor internal terbagi dalam jumlah dan kualitas dosen yang memadai, sarana dan fasilitas yang menunjang, mahasiswa sebagai asset penting yang berpotensi, pelayanan yang memuaskan dan lain-lain. Sedangkan faktor eksternal adalah hubungan perguruan tinggi dengan masyarakat, pemerintah dan perguruan tinggi lainnya. Berdasarkan faktor internal dan eksternal dituntut agar perguruan tinggi memiliki strategi positioning agar tetap survive. Didalam strategi internal yaitu dengan mengoptimalkan sesuatu yang bersifat operasional dalam perguruan tinggi, seperti proses belajar mengajar, mengatur jadwal ruangan, kuliah, jadwal ujian yang kesemuanya merupakan tugas dari bagian pengajaran dan strategi eksternal yaitu strategi agar suatu perguruan tinggi diminati oleh masyarakat, perusahaan dan pemerintah seperti mengadakan seminar, lokakarya, pelatihan dosen dan mahasiswa, mengikuti karya ilmiah, penelitian yang dapat memberikan hasil, tugas belajar untuk dosen agar memiliki jenjang yang lebih tinggi sehingga ilmu yang didapat bertambah luas.

Dalam peningkatan mutu pendidikan adalah syarat utama untuk menghasilkan sumber daya manusia yang mampu berperan dan bersaing secara global. Bisnis pendidikan sekarang semakin kompetitif dalam persaingan penyelenggaraan lembaga pendidikan. Kondisi ini ditunjukkan melalui upaya peningkatan kualitas pengajaran, penelitian, penyediaan fasilitas dan sumber daya insani yang unggul dalam menciptakan jaringan baik di dalam juga di luar negeri. 
Pendayagunaan sistem informasi pada setiap aktivitas internal dalam perguruan tinggi hendaknya sebagai faktor kesuksesan dan kemajuan pada setiap perguruan tinggi. Berbagai kegiatan yang dapat direalisasikan melalui sistem informasi seperti sistem informasi akademik untuk mengelola jadwal perkuliahan, absen dosen dan mahasiswa serta fasilitas entry nilai mahasiswa. Peranan sistem informasi sangat membantu perguruan tinggi memperoleh informasi terkait administrasi akademik dan memfasilitasi segala aktivitas pada perguruan tinggi dalam pengolahan database.

Upaya yang telah dilakukan dalam memenuhi kebutuhan standar pelayanan pendidikan kepada masyarakat, sebagai salah strategi dalam meraih sukses dalam memenangkan persaingan. Strategi penyelenggara jasa pendidikan dalam mengidentifikasi kebutuhan pasar yang perlu mendapat perhatian dari pihak penyelenggara jasa pendidikan tinggi melalui media umpan balik dari mahasiswa atau calon mahasiswa supaya melakukan perubahan organisasi melalui penyebaran angket pelayanan akademik. Misalnya pelayanan pembuatan surat keterangan mahasiswa 1 hari jadi dan merasa senang apabila harapan mereka dilebihi contohnya pelayanan pembayaran SPP bisa dilakukan dimana saja. Kepuasan mahasiswa ditunjukkan melalui loyalitasnya kepada almamater dan pasti akan menghasilkan output yang menguntungkan bagi almamaternya. Dengan melalui angket akan menunjukkan adanya keselarasan antara penilaian konsumen dan keinginan pengelola jasa pendidikan tinggi serta menjadi aspek penting penentu kesuksesan pelaksanaan proses belajar mengajar. Perlu adanya pemenuhan kepuasan yang maksimal dari setiap layanan terbaik yang diberikan perguruan tinggi agar mahasiswa akan merasa puas.

Beberapa peneliti menunjukkan hubungan antara kualitas layanan, kepuasan siswa dan loyalitas siswa dan memodelkan dinamika yang ada di antara mereka (Johnston, 1995; Teas and Agarwal, 2000; Agarwal dan Teas, 2001). Kualitas pelayanan akademik adalah mengacu kepada jasa layanan akademik yang diberikan institusi/lembaga pendidikan kepada mahasiswa, dalam hal ini STIESIA Surabaya. Kualitas pelayanan akademik yang baik didasarkan pada kinerja berbagai kalangan baik tenaga pendidik, tenaga kependidikan bahkan hingga petugas kebersihan.

Townley et al (2001), memaparkan bahwa kepuasan siswa adalah barometer kualitas layanan dalam pendidikan dan telah menarik perhatian lebih besar dari lembaga pendidikan tinggi dalam mengejar keunggulan kompetitif, dalam hal ini tantangan bagi institusi pendidikan tinggi adalah untuk memahami dan untuk mengatasi sumber utama kepuasan siswa dalam inisiatif pemberian layanan mereka. Dengan mengatasi elemen kualitas layanan yang relevan penting bagi mahasiswa, pada institusi dapat meningkatkan kepuasan melalui faktor kunci yang berkontribusi terhadap manfaat seperti retensi mahasiswa, misalnya dengan komunikasi positif dari mulut ke mulut dimana dapat menampilkan keunggulan kompetitif kepada mahasiswa yang merupakan salah satu stakeholder dari institusi pendidikan tinggi akan merasa puas jika harapan mereka dipenuhi misalnya pelayanan pembayaran SPP bisa dilakukan dimana saja, fasilitas rest room yang bersih dan wangi, fasilitas ruang kelas yang lengkap, pendingin ruangan yang layak dan terawat dengan baik. Kepuasan siswa sebagai sesuatu yang disukai untuk evaluasi subyektif siswa dari berbagai hasil dan pengalaman yang terkait dengan pendidikan, melalui pengalaman yang berulang dalam kehidupan kampus yang terlihat dari loyalitasnya bagi almamater sehingga menghasilkan lulusan yang baik untuk almamaternya (Elliott dan Shin, 2002). 
Dalam layanan jasa pendidikan dengan adanya kesetiaan yang membutuhkan pengembangan hubungan yang kuat dengan siswa pada akhirnya memberikan dasar keuangan untuk kegiatan universitas di masa depan, sebuah institusi pendidikan diuntungkan dari memiliki siswa yang loyal tidak hanya ketika siswa adalah peserta formal, keberhasilan sebuah institusi pendidikan juga tergantung pada kesetiaan mantan siswa (Boulding et al., 1993; Zeithaml et al., 1996). Loyalitas siswa menciptakan citra merek untuk lembaga pendidikan selama dan setelah kehidupan kampus mereka, oleh karena itu loyalitas siswa mengacu pada kesetiaan baik selama dan setelah masa belajar siswa di lembaga pendidikan (HennigThurau et al., 2001).

Hasil rekapitulasi data jumlah mahasiswa yang diperoleh dari bagian kemahasiswaan STIESIA Surabaya ditunjukkan pada tabel 1 berikut:

Tabel 1: Rekapitulasi Mahasiswa STIESIA Surabaya Tahun $2015-2018$
\begin{tabular}{|l|c|c|c|c|}
\hline \multirow{2}{*}{ Program Studi } & \multicolumn{4}{c|}{ Angkatan } \\
\cline { 2 - 5 } & 2018 & 2017 & 2016 & 2015 \\
\hline S1 Akuntansi & 565 & 512 & 521 & 550 \\
\hline S1 Manajemen & 453 & 410 & 454 & 564 \\
\hline D3 Manajemen Perpajakan & 63 & 73 & 90 & 74 \\
\hline D3 Akuntansi & 65 & 77 & 96 & 58 \\
\hline Total & 1146 & 1072 & 1161 & 1246 \\
\hline Sumber: Bagian Kemahasiswaan STIESIA di Surabaya (2018)
\end{tabular}

Sesuai data jumlah penerimaan mahasiswa baru pada tahun 2015 - 2018 menunjukkan tren fluktuatif dibandingkan tahun sebelumnya, hal ini berakibat loyalitas mahasiswa terhadap pelayanan di STIESIA Surabaya belum tercapai. Dengan demikian STIESIA Surabaya perlu melakukan pengukuran tingkat kualitas pelayanan, loyalitas mahasiswa dengan membagikan angket setiap akhir semester oleh pihak pengelola agar memudahkan penilaian apakah pelayanan akademik yang telah diberikan selama ini telah memenuhi keinginan dan kebutuhan mahasiswa. Hal ini menunjukkan bahwa STIESIA Surabaya mampu membuktikan bahwa masih ada mahasiswa yang belum memiliki loyalitas pelayanan.

Sebagai salah satu stakeholder dari institusi pendidikan tinggi, mahasiswa memiliki peranan penting dan strategis dalam berkembangnya kampus. Institusi pendidikan tinggi harus selalu melakukan kajian dan evaluasi secara menyeluruh dan berkelanjutan pada sistem birokasi pelayanan akademik agar tercipta persepsi yang positif yang berdampak kepuasan mahasiswa dan timbulnya loyalitas mahasiswa dengan lembaga pendidikan.

\section{Tinjauan Pustaka}

\section{a. Kualitas Pelayanan (Service Quality)}

O'Neill dan Palmer (2004) mendefinisikan kualitas layanan dalam pendidikan tinggi sebagai perbedaan antara apa yang diharapkan siswa untuk diterima dan persepsi tentang pengiriman aktual. Sementara, Zeithaml dan Bitner (2002) menjelaskan kualitas pelayanan ialah derajat keunggulan yang diekspektasikan dan pengendalian atas derajat keunggulan tersebut untuk memenuhi kemauan pelanggan. Dengan demikian terdapat 2 faktor utama yang mempengaruhi kualitas pelayanan (jasa), 
yakni : expected service dan perceived service dimana pelayanan (jasa) yang diterima atau dinikmati (perceived service) sesuai dengan yang kehendaki (expected service), maka kualitas pelayanan (jasa) dipersepsikan baik dan memuaskan".

Dalam Hardiansyah (2011), Zeithaml dan kawan-kawan (1990) mengatakan bahwa SERVQUAL merupakan suatu metode yang diperoleh dari pengamatan bisa digunakan oleh perusahaan/organisasi jasa dalam rangka peningkatkan kualitas pelayanan, metode ini meliputi pengembangan pemahaman mengenai kebutuhan layanan yang dirasakan oleh pelanggan yang pengukurannya diperoleh dari persepsi kualitas layanan bagi organisasi yang bersangkutan serta melakukan adanya analisis kesenjangan yang dihasilkan agar dapat digunakan sebagai pedoman dalam peningkatan kualitas layanan".

\section{b. Dimensi Kualitas Pelayanan (Service Quality)}

Zeithaml dan kawan-kawan juga menjelaskan bahwa adanya perbedaan antara persepsi dan harapan yang mendasari munculnya konsep gap dan digunakan sebagai dasar skala SERVQUAL, yang didasarkan pada lima dimensi kualitas yaitu (1) tangibles, yakni ketersediaan sarana dan prasarana belajar mengajar, fasilitas pendukung, penampilan dosen dan pegawai yang meliputi fasilitas fisik, peralatan, personel, dan media komunikasi; (2) realibility, yaitu kapabilitas dalam memberikan pelayanan yang dijanjikan tepat waktu dan memuaskan; (3) responsiveness, yakni yakni kemampuan dosen dan pegawai untuk membantu dan melayani mahasiswa dengan cepat dengan keterampilan para staf untuk membantu para konsumen dan memberikan pelayanan yang responsif; (4) assurance, yakni pengetahuan yang diperoleh, kurikulum yang memberikan kepastian di masa depan, kompetensi dosen dan pegawai yang meliputi keterampilan, etiket, keraguan; (5) emphaty, yakni perhatian khusus serta memahami keinginan dan kebutuhan mahasiswa yang meliputi kemudahan dalam melakukan jalinan komunikasi yang baik dan memahami kebutuhan para konsumen.

\section{c. Analisis Kesenjangan Kualitas Pelayanan}

Lupiyoadi (2009) menjelaskan bawah terdapat lima kesenjangan (gap) yang menyebabkan adanya perbedaan persepsi mengenai kualitas pelayanan, seperti yang ditunjukkan pada Gambar 1 yaitu (1) gap persepsi manajemen, yaitu adanya perbedaan antara penilaian pelayanan menurut pengguna jasa dan persepsi manajemen mengenai harapan pengguna jasa, kesenjangan ini terjadi karena kurangnya orientasi penelitian pemasaran, pemanfaatan yang tidak memadai atas temuan penelitian, kurangnya interaksi antara pihak manajemen dan pelanggan, komunikasi dari bawah ke atas yang kurang memadai, serta terlalu banyaknya tingkatan manajemen; (2) gap spesifikasi kualitas, yaitu kesenjangan antara persepsi manajemen mengenai harapan pengguna jasa dan spesifikasi kualitas jasa. kesenjangan terjadi antara lain karena tidak memadainya komitmen manajemen terhadap kualitas jasa, persepsi mengenai ketidaklayakan, tidak memadainya standarisasi tugas dan tidak adanya penyusunan tujuan; (3) gap penyampaian pelayanan, yaitu kesenjangan antara spesifikasi kualitas jasa dan penyampaian jasa (service delivery), kesenjangan ini terutama disebabkan oleh faktor-faktor: (a) ambiguitas peran, yaitu sejauh mana pegawai dapat 
melakukan tugas sesuai dengan harapan manajer tetapi memuaskan pelanggan. sedangkan (b) konflik peran, yaitu sejauhmana pegawai meyakini bahwa mereka tidak memuaskan semua pihak, (c) kesesuaian pegawai dengan tugas yang harus dikerjakan, (d) kesesuaian teknologi yang digunakan pegawai, (e) sistem pengendalian dari atasan, yaitu tidak memadainya sistem penilaian dan sistem imbalan, (f) perceived control, yaitu sejauhmana pegawai merasakan kebebasan atau fleksibilitas untuk menentukan cara pelayanan, (g) teamwork, yaitu sejauh mana pegawai dan manajemen merumuskan tujuan bersama di dalam memuaskan pelanggan secara bersama-sama dan terpadu; gap komunikasi pemasaran, yaitu kesenjangan antara penyampaian jasa dan komunikasi eksternal dengan ekspektasi pelanggan mengenai kualitas pelayanan dipengaruhi oleh pernyataan yang dibuat oleh perusahaan melalui komunikasi pemasaran, kesenjangan ini terjadi karena (a) tidak memadainya komunikasi horizontal, (b) adanya kecenderungan untuk memberikan janji yang berlebihan hal ini menunjukkan adanya komunikasi eksternal telah mendistorsi harapan pelanggan; (4) gap dalam pelayanan yang dirasakan, adalah perbedaan persepsi antara jasa yang dirasakan dan yang diharapkan oleh pelanggan, jika keduanya terbukti sama maka perusahaan akan memperoleh citra dan dampak positif namun apabila yang diterima lebih rendah dari yang diharapkan maka kesenjangan ini akan menimbulkan permasalahan bagi perusahaan.

Gambar 1. Analisis Lima Kesenjangan

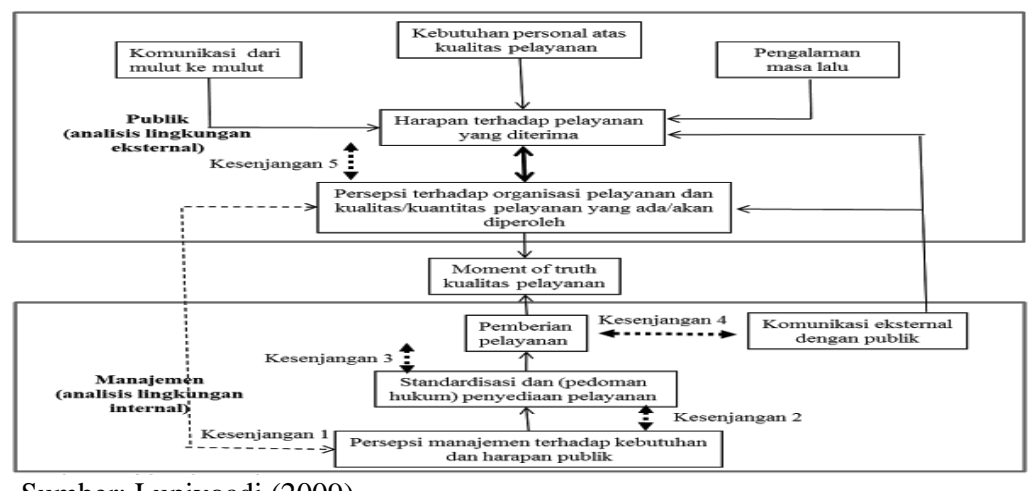

Sumber: Lupiyoadi (2009)

\section{d. Kepuasan (Satisfaction)}

Kepuasan siswa adalah barometer kualitas layanan dalam pendidikan dan telah menarik perhatian lebih besar dari lembaga pendidikan tinggi dalam mengejar keunggulan kompetitif dan tantangan bagi institusi (Townley et al,2001). Dengan mengatasi elemen kualitas layanan yang relevan penting bagi mahasiswa internasional, universitas dapat meningkatkan kepuasan siswa. Faktor kunci yang berkontribusi terhadap manfaat seperti retensi siswa, komunikasi positif dari mulut ke mulut, dan keunggulan kompetitif, selain itu mahasiswa yang merupakan salah satu stakeholder dari institusi pendidikan akan merasa puas jika harapan mereka dipenuhi misalnya pelayanan pembayaran SPP bisa dilakukan dimana saja, fasilitas rest room yang bersih dan wangi, ruang kelas yang lengkap, pendingin ruangan yang memadai dan bersih.

Elliott dan Shin (2002) menjelaskan pula bahwa kepuasan siswa sebagai sesuatu yang disukai untuk ulasan personal siswa oleh karena berbagai hasil serta pengetahuan pada dunia pendidikan, 
melalui pengalaman yang berulang dalam kehidupan kampus yang tampak dari loyalitasnya bagi almamater sehingga menghasilkan lulusan yang baik untuk almamaternya.

\section{e. Loyalitas (Customer Loyalty)}

Dalam layanan jasa pendidikan dengan adanya kesetiaan yang membutuhkan pengembangan hubungan yang kuat dengan siswa pada akhirnya memberikan dasar keuangan untuk kegiatan universitas di masa depan, sebuah institusi pendidikan diuntungkan dari memiliki siswa yang loyal tidak hanya ketika siswa adalah peserta formal, keberhasilan sebuah institusi pendidikan juga tergantung pada kesetiaan mantan siswa (Boulding et al., 1993; Zeithaml et al., 1996). Loyalitas siswa menciptakan citra merek untuk lembaga pendidikan selama dan setelah kehidupan kampus mereka, oleh karena itu loyalitas siswa mengacu pada kesetiaan baik selama dan setelah masa belajar siswa di lembaga pendidikan (Hennig-Thurau et al., 2001).

Lupiyoadi (2009) pelanggan yang loyal akan menunjukkan ciri-ciri sebagai berikut : Repeat, apabila pelanggan memerlukan produk atau jasa berkenan membeli produk tersebut di perusahaan tersebut; Retention, pelanggan tidak tergoda akan pelayanan yang ditawarkan oleh pihak lain; Refferal, kalau produk atau jasa baik, pelanggan bakal mempromosikan kepada orang lain, dan bila buruk pelanggan diam dan memberitahukannya pada pihak perusahaan.

\section{Metode Penelitian}

\section{a. Jenis Penelitian}

Pendekatan pada penelitian ini memanfaatkan metode survey eksplanatory dengan pendekatan kuantitatif. Metode penelitian kuantitatif bisa didefiniskan sebagai metode penelitian yang berlandaskan pada sampel filsafat positivisme, dimanfaatkan untuk meneliti pada populasi atau sampel tertentu, pengumpulan data memanfaatkan instrumen penelitian, analisis data bersifat kuantitatif/statistik, dengan tujuan untuk menguji hipotesis yang telah ditetapkan (Sugiyono, 2017). Dalam memperoleh data riset ini menggunakan metode survey. Metode survey ialah riset yang dilakukan dengan memanfaatkan angket sebagai alat penelitian yang dilakukan pada populasi besar maupun kecil, tetapi data yang dipelajari yakni data dari sampel yang diambil dari populasi tersebut, sehingga ditemukan kejadian relatif, distribusi, dan hubungan antar variabel, sosiologis maupun psikologis (Sugiyono, 2017).

\section{b. Populasi dan Sampel Penelitian}

Populasi pada penelitian ini yaitu mahasiswa program studi sarjana dan diploma kampus STIESIA Surabaya. Populasi adalah wilayah generalisasi yang terdiri atas; subyek/obyek yang memiliki kualitas dan karakteristik tertentu yang ditetapkan oleh peneliti untuk dipelajari dan kemudian ditarik kesimpulannya (Sugiyono, 2017).

Dari penelitian ini diketahui menjadi 98 responden mahasiswa yang dipakai sebagai sampel riset. Sampel adalah bagian dari jumlah dan karakteristik yang dimiliki oleh populasi (Sugiyono, 2017). Mengingat besarnya jumlah populasi di atas, maka penulis menentukan jumlah sampel menggunakan rumus Slovin (Sugiyono, 2017). 


\section{Hasil Penelitian dan Pembahasan}

\section{Uji Kelayakan Model}

\section{a. Validitas}

Hasil pengujian validitas pada 27 butir pertanyaan variabel $\mathrm{X}_{1}, \mathrm{X}_{2}, \mathrm{X}_{3}, \mathrm{X}_{4}, \mathrm{X}_{5}, \mathrm{Y}_{1}, \mathrm{Y}_{2}$, diketahui valid sesuai nilai koefisien $r>0.30$ sebagai berikut :

Tabel 2. Uji Validitas Variabel Bukti Fisik $\left(\mathrm{X}_{1}\right)$

\begin{tabular}{|c|c|c|c|}
\hline Item & Korelasi Pearson & Kriteria & Keterangan \\
\hline $\mathrm{X}_{1.1}$ & 0.699 & 0.300 & Valid \\
\hline $\mathrm{X}_{1.2}$ & 0.709 & 0.300 & Valid \\
\hline $\mathrm{X}_{1.3}$ & 0.737 & 0.300 & Valid \\
\hline $\mathrm{X}_{1.4}$ & 0.744 & 0.300 & Valid \\
\hline $\mathrm{X}_{1.5}$ & 0.703 & 0.300 & Valid \\
\hline $\mathrm{X}_{1.6}$ & 0.718 & 0.300 & Valid \\
\hline $\mathrm{X}_{1.7}$ & 0.697 & 0.300 & Valid \\
\hline $\mathrm{X}_{1.8}$ & 0.690 & 0.300 & Valid \\
\hline $\mathrm{X}_{1.9}$ & 0.691 & 0.300 & Valid \\
\hline $\mathrm{X}_{1.10}$ & 0.726 & 0.300 & Valid \\
\hline
\end{tabular}

Tabel 3 Uji Validitas Variabel Keandalan $\left(\mathrm{X}_{2}\right)$

\begin{tabular}{|c|c|c|c|}
\hline Item & Korelasi Pearson & Kriteria & Keterangan \\
\hline $\mathrm{X}_{2.1}$ & 0.684 & 0.300 & Valid \\
\hline $\mathrm{X}_{2.2}$ & 0.695 & 0.300 & Valid \\
\hline $\mathrm{X}_{2.3}$ & 0.694 & 0.300 & Valid \\
\hline $\mathrm{X}_{2.4}$ & 0.692 & 0.300 & Valid \\
\hline $\mathrm{X}_{2.5}$ & 0.678 & 0.300 & Valid \\
\hline
\end{tabular}

Tabel 4 Uji Validitas Variabel Daya Tanggap $\left(\mathrm{X}_{3}\right)$

\begin{tabular}{|c|c|c|c|}
\hline Item & Korelasi Pearson & Kriteria & Keterangan \\
\hline $\mathrm{X}_{3.1}$ & 0.696 & 0.300 & Valid \\
\hline $\mathrm{X}_{3.2}$ & 0.688 & 0.300 & Valid \\
\hline $\mathrm{X}_{3.3}$ & 0.686 & 0.300 & Valid \\
\hline
\end{tabular}

Tabel 5 Uji Validitas Variabel Jaminan (X4)

\begin{tabular}{|c|c|c|c|}
\hline Item & Korelasi Pearson & Kriteria & Keterangan \\
\hline $\mathrm{X}_{4.1}$ & 0.696 & 0.300 & Valid \\
\hline $\mathrm{X}_{4.2}$ & 0.684 & 0.300 & Valid \\
\hline $\mathrm{X}_{4.3}$ & 0.691 & 0.300 & Valid \\
\hline $\mathrm{X}_{4.4}$ & 0.682 & 0.300 & Valid \\
\hline
\end{tabular}

Tabel 6 Uji Validitas Variabel Empati (X5)

\begin{tabular}{|c|c|c|c|}
\hline Item & Korelasi Pearson & Kriteria & Keterangan \\
\hline $\mathrm{X}_{5.1}$ & 0.688 & 0.300 & Valid \\
\hline $\mathrm{X}_{5.2}$ & 0.685 & 0.300 & Valid \\
\hline $\mathrm{X}_{5.3}$ & 0.670 & 0.300 & Valid \\
\hline $\mathrm{X}_{5.4}$ & 0.673 & 0.300 & Valid \\
\hline $\mathrm{X}_{5.5}$ & 0.699 & 0.300 & Valid \\
\hline
\end{tabular}

Tabel 7 Uji Validitas Variabel Kepuasan Mahasiswa (Y1)

\begin{tabular}{|c|c|c|c|}
\hline Item & Korelasi Pearson & Kriteria & Keterangan \\
\hline $\mathrm{Y}_{1.1}$ & 0.671 & 0.300 & Valid \\
\hline $\mathrm{Y}_{1.2}$ & 0.692 & 0.300 & Valid \\
\hline $\mathrm{Y}_{1.3}$ & 0.634 & 0.300 & Valid \\
\hline $\mathrm{Y}_{1.4}$ & 0.622 & 0.300 & Valid \\
\hline $\mathrm{Y}_{1.5}$ & 0.629 & 0.300 & Valid \\
\hline
\end{tabular}

Tabel 8 Uji Validitas Variabel Loyalitas Mahasiswa (Y2)

\begin{tabular}{|c|c|c|c|}
\hline Item & Korelasi Pearson & Kriteria & Keterangan \\
\hline $\mathrm{Y}_{2.1}$ & 0.671 & 0.300 & Valid \\
\hline $\mathrm{Y}_{2.2}$ & 0.692 & 0.300 & Valid \\
\hline $\mathrm{Y}_{2.3}$ & 0.634 & 0.300 & Valid \\
\hline
\end{tabular}


Validitas menunjukan derajat ketepatan antara data yang sesungguhnya terjadi pada objek dengan data yang dikumpulkan oleh peneliti untuk mencari validitas sebuah item dengan mengkorelasikan skor item dengan total item-item tersebut, jika koefisien antara item dengan total item sama atau diatas 0,3 maka item tersebut dinyatakan valid apabila nilai korelasinya dibawah 0,3 maka item tersebut dinyatakan tidak valid (Sugiyono, 2017).

\section{b. Reliabilitas}

Hasil pengujian validitas pada 27 butir pertanyaan variabel $\mathrm{X}_{1}, \mathrm{X}_{2}, \mathrm{X}_{3}, \mathrm{X}_{4}, \mathrm{X}_{5}, \mathrm{Y}_{1}, \mathrm{Y}_{2}$, diketahui valid sesuai nilai Cronbach Alpha > 0.60 sebagai berikut:

Tabel 9 Uji Reliabilitas Variabel Penelitian

\begin{tabular}{|l|c|c|c|}
\hline \multicolumn{1}{|c|}{ Variabel } & Cronbach Alpha & Kriteria & Keterangan \\
\hline Bukti Fisik $\left(\mathrm{X}_{1}\right)$ & 0.899 & 0.60 & Reliabel \\
\hline Keandalan $\left(\mathrm{X}_{2}\right)$ & 1.113 & 0.60 & Reliabel \\
\hline Daya Tanggap $\left(\mathrm{X}_{3}\right)$ & 1.388 & 0.60 & Reliabel \\
\hline Jaminan $\left(\mathrm{X}_{4}\right)$ & 0.858 & 0.60 & Reliabel \\
\hline Empati $\left(\mathrm{X}_{5}\right)$ & 0.898 & 0.60 & Reliabel \\
\hline Kepuasan Mahasiswa $\left(\mathrm{Y}_{1}\right)$ & 1.149 & 0.60 & Reliabel \\
\hline Loyalitas $\left(\mathrm{Y}_{2}\right)$ & 0.697 & 0.60 & Reliabel \\
\hline
\end{tabular}

Uji reliabilitas berguna untuk menetapkan apakan instrumen yang dapat dipakai lebih dari satu kali paling tidak oleh responden yang sama akan menghasilkan data yang konsisten dimana nilai reliabilitas dinyatakan dengan koefisien alpha cronbach sesuai kriteria batas terendah reliabilitas yaitu 0,6 dan apabila kriteria pengujian terpenuhi maka kuesioner dinyatakan reliable setelah dilakukan uji instrumen penelitian tahap selanjutnya adalah memilih metode analisis data yang digunakan dan melakukan pengujian terhadap hipotesis penelitian (Sugiyono, 2017).

\section{Uji Hipotesis}

Peneliti dalam riset ini memanfaatkan persamaan regresi linear berganda karena variabel bebas dalam penelitian lebih dari satu. Apabila peneliti melakukan peramalan dengan kondisi (naik turunnya) variabel dependen (kriterium) sedangkan bila dua atau lebih variabel independen sebagai faktor predictor dimanipulasi (dinaik turunkan nilainya maka analisis regresi berganda akan dilakukan bila jumlah variabel independennya minimal 2 (Sugiyono, 2017).

\section{Hasil Penelitian}

\section{Pengaruh langsung kualitas pelayanan terhadap kepuasan mahasiswa.}

Pengujian hipotesis untuk sub hipotesis penelitian pertama tentang pengaruh kualitas pelayanan (X) terhadap kepuasan mahasiswa (Y1). Untuk melakukan uji sub-hipotesis pertama ini melalui regresi berganda pada persamaan berikut menggunakan software SPSS versi 23:

\section{$\mathrm{Y}_{1}=\beta Y 1 \mathrm{X}+\beta \mathrm{Y} 1 \mathrm{E} 1 \ldots . . . . . . . .$. Persamaan 1}

Tabel 10 Regresi Sub Struktur Pertama

Model Summary

\begin{tabular}{|c|c|c|c|c|}
\hline \multicolumn{5}{|c|}{ Model Summary } \\
\hline Model & $\mathrm{R}$ & R Square & Adjusted R Square & $\begin{array}{l}\text { Std. Error of the } \\
\text { Estimate }\end{array}$ \\
\hline 1 &, $740^{\mathrm{a}}$ & ,548 & ,543 & 1,417 \\
\hline
\end{tabular}




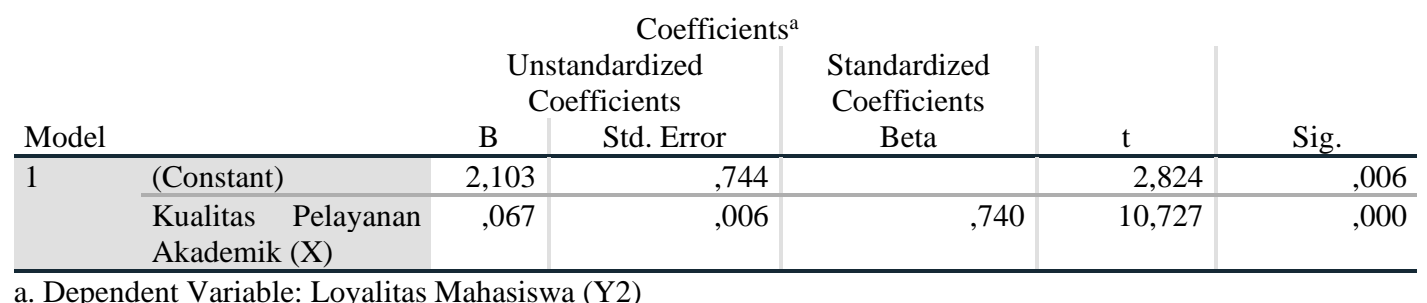

Melihat uji hipotesis dari regresi sub struktur pertama pada persamaan (1) dari tabel 10 dengan nilai - nilai standardized coefficients beta pada tabel diatas ialah hasil nilai koefisien regresi pada data yang telah dibakukan dan bisa dipastikan nilai koefisien regresi tersebut adalah nilai koefisien jalur dari nilai tersebut dapat gambarkan hubungan struktur pertama terdapat pada Gambar 2.

Gambar 2 Hubungan Sub Struktur Pertama

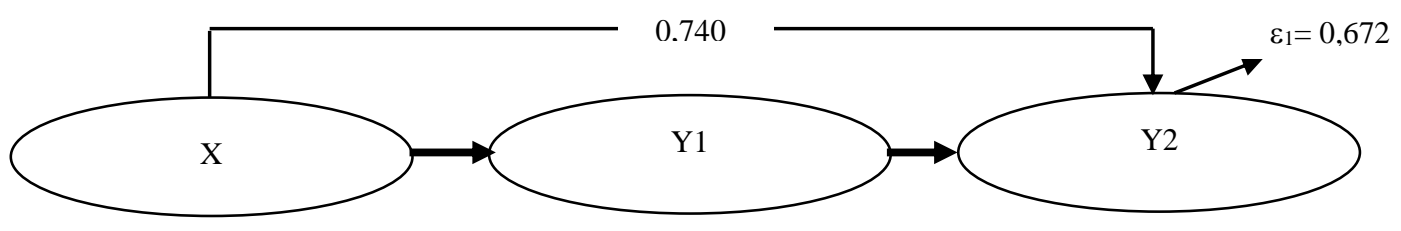

Uji hipotesis pada penelitian ini melihat pengaruh dari setiap variabel $\mathrm{X}$ terhadap variabel $\mathrm{Y} 2$ dilakukan dengan membandingkan nilai sig. $\mathrm{t}$ lebih kecil dari nilai $\alpha=0,05$ dan menunjukkan pengaruh secara signifikan pada variabel X terhadap Y2. Melihat ouput uji hipotesis pertama ini mengindikasikan keberadaan temuan bahwa kualitas pelayanan akademik berpengaruh secara langsung terhadap kepuasan mahasiswa.

\section{Pengaruh langsung kualitas pelayanan terhadap kepuasan mahasiswa.}

Pelaksanaan uji hipotesis untuk sub hipotesis struktur kedua tentang pengaruh kualitas pelayanan (X) dan kepuasan mahasiswa (Y1) terhadap loyalitas mahasiswa (Y2). Untuk mengetahui output uji hipotesis sub-struktur kedua ini dilakukan melalui regresi berganda pada persamaan berikut menggunakan program SPSS versi 23:

\section{$Y_{2}=\beta Y 2 X+\beta Y 2 Y 1+\beta Y 2 \varepsilon 2 \ldots . . . P e r s a m a a n ~ 2$}

Tabel 11. Regresi Sub Struktur Kedua

\begin{tabular}{|c|c|c|c|c|}
\hline \multicolumn{5}{|c|}{ Model Summary } \\
\hline Model & $\mathrm{R}$ & R Square & $\begin{array}{l}\text { Adjusted R } \\
\text { Square }\end{array}$ & Std. Error of the Estimate \\
\hline 1 &, $747^{\mathrm{a}}$ & 558 & ,548 & 1,409 \\
\hline
\end{tabular}

\begin{tabular}{|c|c|c|c|c|c|c|}
\hline \multirow{2}{*}{\multicolumn{2}{|c|}{ Model }} & \multicolumn{2}{|c|}{$\begin{array}{l}\text { Unstandardized } \\
\text { Coefficients }\end{array}$} & \multirow{2}{*}{$\begin{array}{c}\text { Standardized } \\
\text { Coefficients } \\
\text { Beta }\end{array}$} & \multirow[b]{2}{*}{$\mathrm{t}$} & \multirow[b]{2}{*}{ Sig. } \\
\hline & & $\mathrm{B}$ & Std. Error & & & \\
\hline \multirow[t]{3}{*}{1} & (Constant) & 2,048 & ,741 & & 2,763 &, 007 \\
\hline & Kualitas Pelayanan Akademik (X) &, 103 & , 026 & 1,142 & 3,979 &, 000 \\
\hline & Kepuasan Mahasiswa (Y1) &,- 142 & ,098 &,- 414 & $-1,443$ &, 152 \\
\hline
\end{tabular}

a. Dependent Variable: Loyalitas Mahasiswa (Y2) 
Output uji hipotesis pada persamaan (2) pada tabel 11 dari nilai - nilai standardized coefficients beta pada tabel 11 yaitu output nilai koefisien regresi untuk data yang sudah dibakukan maka diketahui output dari nilai koefisien regresi tersebut adalah nilai koefisien jalur dari nilai tersebut dapat diilustrasikan pada hubungan struktur kedua terdapat pada Gambar 3.

Gambar 3. Hubungan Sub Struktur Kedua

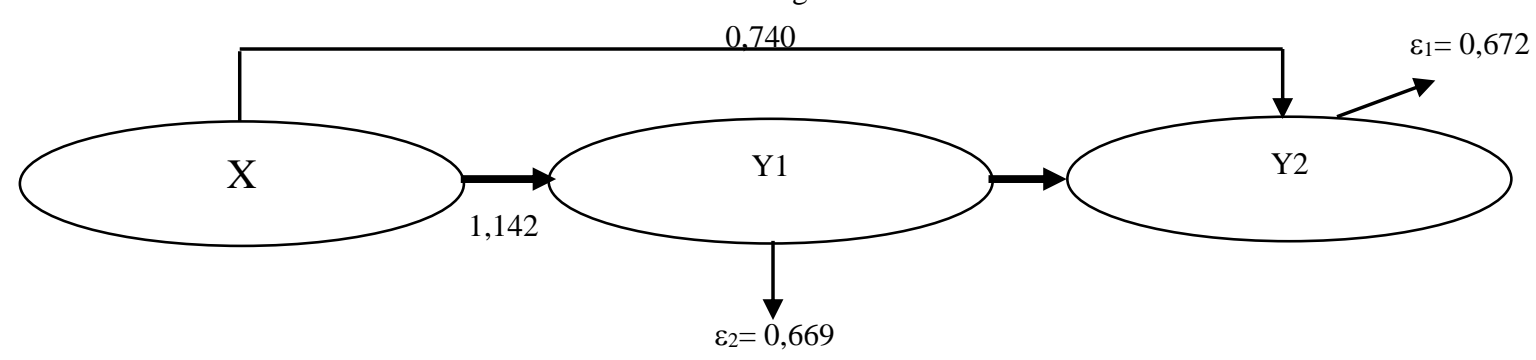

Uji hipotesis riset pada pengaruh dari setiap variabel $\mathrm{X}$ dan variabel $\mathrm{Y} 1$ terhadap variabel $\mathrm{Y} 2$ dilakukan melalui perbandingan nilai sig. $\mathrm{t}$ lebih kecil dari nilai $\alpha=0,05$ melihat output SPSS dari variabel Y1 nilai sig.t lebih besar dari $\alpha=0,05$ yang diketahui output variabel Y1 tidak berpengaruh secara signifikan terhadap variabel $Y 2$, maka hanya variabel $X$ yang memiliki nilai sig.t lebih kecil dari $\alpha$ $=0,05$ bahwa variabel $\mathrm{X}$ memiliki pengaruh secara signifikan terhadap variabel Y2.

Merujuk pada ouput hubungan struktur kedua ini mengindikasikan temuan bahwa kepuasan mahasiswa tidak berpengaruh langsung pada loyalitas mahasiswa, hanya variabel kualitas pelayanan akademik yang memiliki pengaruh lagsung terhadap loyalitas mahasiswa.

Merujuk pada hasil intervening pada gambar 3, maka dapat dikatakan bahwa intervening yang terjadi adalah mediasi penuh (complete intervening), dikarenakan ada pengaruh langsung dari $\mathrm{X}$ ke $\mathrm{Y} 2$, dan tidak terdapat pengaruh secara langsung dari $\mathrm{X}$ ke $\mathrm{Y} 2$ melewati $\mathrm{Y}$ 1. Perhitungan detail pengaruh total dari X ke Y2 melewati Y1 berikut ini :

a. Pengaruh langsung dari $\mathrm{X}$ ke $\mathrm{Y} 2$ sejumlah 1,142 .

b. Pengaruh Tidak Langsung dari X ke Y2 melewati Y1 sejumlah 0,740 x $(-0,414)=-0,306$

c. Pengaruh keseluruhan sejumlah $1,142+(-0,306)=0,836$

\section{Pembahasan}

\section{Hipotesis Pada Sub Struktur Pertama}

Melihat output SPSS hipotesis pada struktur pertama mendeskripsikan bahwa variabel kualitas pelayanan akademik (X) berpengaruh langsung terhadap loyalitas mahasiswa (Y2) diperoleh hasil t pada variabel kualitas pelayanan akademik (X) diketahui nilai t sebesar 10.727 dan hasil signifikan sebesar 0.000 bermakna $\alpha>0.05$, maka Ho diterima dan Ha ditolak dapat disimpulkan bahwa variabel kualitas pelayanan akademik (X) berpengaruh secara langsung terhadap loyalitas mahasiswa (Y2) STIESIA Surabaya. 
Temuan riset ini membuktikan peran fasillitas pendukung kualitas pelayanan akademik terkait dengan 1) Sarana dan prasarana fisik yang memadai, 2) Pelayanan administrasi sesuai standar operasional, 3) Pelayanan yang ramah dan cepat (responsif) kepada stakeholder melalui penyediaan informasi yang jelas, 4) Pengetahuan yang memadai, sikap sopan dan murah senyum, dan kemampuan para tenaa kependidikan mampu menumbuhkan rasa percaya para mahasiswa/stakeholder serta 5) Memahami kebutuhan pelanggan secara spesifik, yang berdampak pada meningkatnya kesetian/loyalitas mahasiswa terkait dengan komitmen yang ditunjukkan mahasiswa dapat dilakukan dalam bentuk memberikan rekomendasi STIESIA Surabaya kepada masyarakat luas, menjaga nama baik almamater dan menceritakan hal-hal yang positif serta memberikan sharing pengalaman terkait pelayanan dan fasilitas pendukung selama studi. Sari (2017) dalam penelitiannya menemukan variabel kualitas pelayanan mempunyai pengaruh positif dan signifikan terhadap loyalitas pelanggan dengan nilai hasil uji $\mathrm{F}$ sebesar 20.160 dengan nilai signifikansi sebesar $0.000<0.05$. Temuan ini juga menguatkan temuan lainnya bahwa hasil layanan pendidikan berpengaruh positif dan signifikan terhadap loyalitas siswa, serta terdapat korelasi positif dan langsung antara kualitas layanan dan kesetiaan (Hennig-Thurau et al., 2001; Cronin et al., 2000).

\section{Hipotesis Pada Sub Struktur Kedua}

Melihat output SPSS uji hipotesis struktur kedua menerangkan ekistensi kualitas pelayanan akademik (X) tidak dipengaruh langsung kepada loyalitas mahasiswa (Y2) melalui kepuasan mahasiswa (Y1) diketahui output nilai $t$ pada variabel kualitas pelayanan akademik (X) yaitu 3.979 dengan signifikan sebesar 0.000 berarti $\alpha>0.05$, maka Ho diterima dan Ha ditolak. Perasaan puas muncul dari pengalaman yang berulang dalam kehidupan kampus dan tergambarkan dari loyalitasnya kepada almamater dan tentunya akan menghasilkan lulusan yang baik untuk almamaternya, temuan riset telah membuktikan bahwa kepuasan mahasiswa atas dasar kesenangan dan keinginan berulang atas dasar rasionalitas denan demikian peran penting kualitas pelayanan akademik kepada loyalitas mahasiswa, dan tidak berpengaruh secara langsung dari kualitas pelayanan akademik kepada loyalitas mahasiswa melalui kepuasan mahasiswa. Syahputra (2010) menunjukkan bahwa kualitas pelayanan akademik berpengaruh tidak langsung secara signifikan terhadap loyalitas mahasiswa dengan Kepuasan Mahasiswa sebagai variabel intervening. Sedangkan, Annamdevula dan kawan-kawan (2016) memperlihatkan hasil peran mediasi parsial dan simultan dari variabel kepuasan siswa antara persepsi kualitas layanan siswa, loyalitas dan motivasi mereka terhadap layanan yang diberikan oleh universitas.

\section{Kesimpulan}

Uji hipotesis secara parsial mendeskripsikan bahwa tangible, reliability, dan responsiveness tidak dipengaruhi oleh loyalitas mahasiswa STIESIA Surabaya. Sementara itu, peran kualitas pelayanan akademik tidak dipengaruhi langsung oleh loyalitas mahasiswa melalui kepuasan mahasiswa sebagai variabel intervening, dalam penelitian ini terbukti bahwa kepuasan mahasiswa dari adanya pengalaman 
yang berulang dalam kehidupan kampus dan tergambar pada loyalitasnya terhadap almamater dan pastinya akan menciptakan alumnus yang berdaya guna untuk kampusnya. Di lain pihak, Yayasan Perpendiknas sebagai badan hukum pengelola jasa pendidikan harus merespon dengan cepat temuan penelitian dengan adanya perasaan kurang puas yang dialami mahasiswa pada kualitas pelayanan akademik yang diharapkan mahasiswa sebagai stakeholder. Perasaan kurang puas yang dialami mahasiswa pada pelayanan akademik yang diberikan oleh tenaga kependidikan dapat diketahui dari hasil evaluasi persepsi mahasiswa melalui angket, maka disarankan kepada Yayasan Perpendiknas melalui STIESIA Surabaya perlu melakukan peningkatan softskill tenaga kependidikan agar lebih responsif dalam melayani mahasiswa.

\section{Daftar Pustaka}

Annamdevula, S and Bellamkonda, R.S. (2016). The effects of service quality on student loyalty: the mediating role of student satisfaction, Journal of Modelling in Management. Vol. 11 No. 2, 2016 pp. 446-462.

Boulding, W. et al. (1993). A Dynamic Process Model of Service Quality: Form Expectations to Behavioral Intentions. Journal of Marketing Research. Vol. 30, pp. 7-27.

Cronin, J.J. Jr, Brady, M.K. and Hult, G.T.M. (2000). Assessing the effects of quality, value, and customer satisfaction on consumer behavioral intentions in service environments, Journal of Retailing, Vol. 76 No. 2, pp. 193-218.

Davis, G. F., Yoo, M., \& Baker, W. E. (2003). The Small World of the American Corporate Elite, 19822001. Strategic Organization, 1(3), 301-326. https://doi.org/10.1177/14761270030013002

Elliott, K.M. and Shin, D. (2002), Student satisfaction: an alternative approach to assessing this important concept, Journal of Higher Education Policy and Management, Vol. 24 No. 2, pp. 197209.

Hardiansyah. (2011). Kualitas Pelayanan Publik. Yogyakarta: Gava Media.

Hennig-Thurau, T., Langer, M.F. and Hansen, U. (2001), Modeling and managing student loyalty an approach based on the concept of relationship quality, Journal of Service Research, Vol. 3 No. 4, pp. 331-344.

Lupiyoadi, Rambat, dan Hamdani. (2009). Manajemen Pemasaran Jasa, Edisi II. Jakarta: Salemba Empat.

Marmolejo. (2017). Proses Pembelajaran Digital dalam Era Revolusi Industri 4.0, [PDF document], diakses

dari (http://baakk.unnes.ac.id/download.php?file=V,1,1\%20Dirjen\%20Belmawa\%20IA_Belmawa-

Rakernas-Ristekdikti-Medan-Final-16-01-18.pdf

O'Neill, M.A. and Palmer, A. (2004), Importance-performance analysis: a useful tool for directing continuous quality improvement in higher education, Quality Assurance in Education, Vol. 12 No. 1, pp. 39-52. 
Putra, Alriko. (2010). Analisis pengaruh persepsi keadilan organisasi terhadap komitmen organisasi (Studi kasus: PT. X). Skripsi. Fakultas Ekonomi Universitas Indonesia.

Safrian, A,. Neni, M,. Yessica, S,. Arridha, Z.S. (2015). Peranan Sistem Informasi Dalam Perguruan Tinggi, Jurnal Teknologi dan Sistem Informasi, Volume 1, Nomor 2, Maret 2015, hlm 79-86.

Sari, G. (2017). Pengaruh Kualitas Pelayanan Terhadap Loyalitas Pelanggan Dengan Kepuasan Pelanggan Sebagai Variabel Intervening Pada Warung Nasi Ibu Sri Medan. Tesis. Sekolah Pascasarjana Universitas Sumatera Utara Medan.

Sugiyono. (2017). Metode Penelitian Kuantitatif, Kualitatif, dan R\&D. Bandung: Alfabeta, CV.

Syahputra, M.H. (2017). Analisis Pengaruh Kualitas Pelayanan Terhadap Kepuasan Dan Loyalitas Occupant Pada Hotel Lido Graha Di Lhokseumawe. Tesis. Sekolah Pascasarjana Universitas Sumatera Utara Medan.

Zeithaml, V. A., A. Parasuraman, and L.L. Berry. (1990). Delivering Quality Service. New York: The Free Press.

Zeithaml, V. A., Berry, L.L. \& Parasuraman, A. (1996). The Behavioural Consequences of Service Quality. Jurnal Of Marketing Management. Vol. 60. pp.31-46.

Zeithaml, Valarie A. and Bitner, Mary Jo. (2002). Service Marketing, McGraw Hill Inc, Int'l Edition, New York.

Zeithaml, V. A. \& Parasuraman, A. \& Malhotra (2002). ESQUAL A Multiple-Item Scale for Assessing Electronic Service Quality. New York: Free Press. 